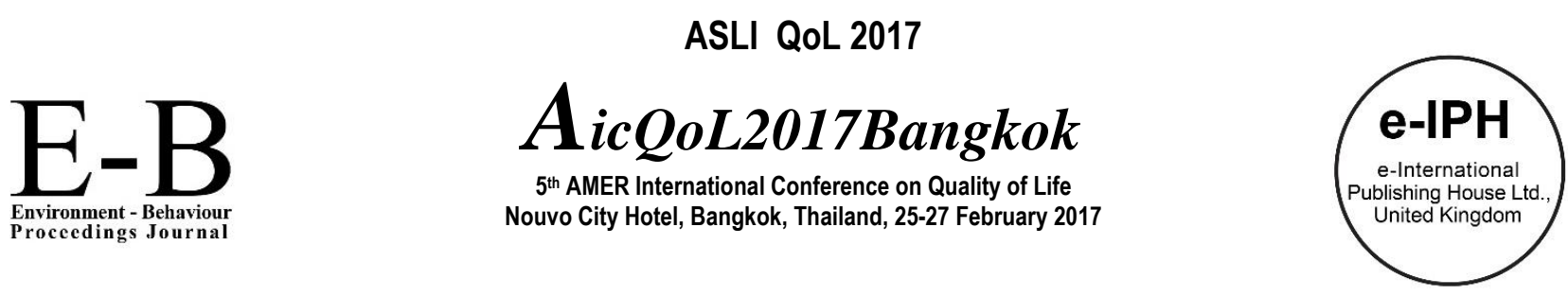

\title{
Development and Validation of an Educational Booklet for Sunnah Practices in Improving Quality of Life
}

\author{
Nur Islami Mohd Fahmi Teng ${ }^{1 *}$, Nashrah Adilah Ismail ${ }^{1}$, Nazrul Hadi Ismail1 ${ }^{1}$ Thuraya Ahmad² \\ ${ }^{1}$ Centre of Nutrition and Dietetics, Faculty of Health Sciences, Universiti Teknologi MARA \\ ${ }^{2}$ Academy of Contemporary Islamic Studies, Universiti Teknologi MARA
}

\begin{abstract}
Sunnah eating practices refers to the practices promoted by Prophet Muhammad (pbuh) that has healthy lifestyle elements. This paper describes the validation process of an educational booklet for sunnah eating practices to improve the Quality of Life among adults population. This study involves three steps; development of the booklet, validation of the booklet by 22 judges, and by 20 adults. The result of the Item-level Content Validity Index (I-CVI) for the booklet exceeds 0.80 . Thus, the booklet was validated and should be used by healthcare professionals to assist on eating practices to improve the quality of life.
\end{abstract}

Keywords: Sunnah; Eating practice; Physical activity; Educational booklet.

ISSN: 2398-4287@ 2017. The Authors. Published for AMER ABRA by e-International Publishing House, Ltd., UK. This is an open access article under the CC BYNC-ND license (http://creativecommons.org/licenses/by-nc-nd/4.0/). Peer-review under responsibility of AMER (Association of Malaysian Environment-Behaviour Researchers), ABRA (Association of Behavioural Researchers on Asians) and CE-Bs (Centre for Environment-Behaviour Studies), Faculty of Architecture, Planning \& Surveying, Universiti Teknologi MARA, Malaysia.

\subsection{Introduction}

The prevalence of overweight in Malaysia is on the rise from the year of 2003 to 2015. According to Malaysia Adult Nutrition Survey (MANS) 2003, the prevalence of overweight in adults is $26.7 \%$ and the prevalence has increased to $29.1 \%$ in the third Malaysian National Health and Morbidity Survey (NHMS III) 2006 (Khor GL et. al, 2008). The prevalence further increased to 29.4\% (NHMS IV) in 2011. In another survey done in 2008, the overall prevalence of overweight is $33.6 \%$ (Mohamud et al., 2011). With the increasing trend in Malaysian of people who are overweight, this matter has been seen as a serious problem. Thus, combating the overweight problem as the root of most diseases is the main concerned.

There are many ways that can be done to overcome overweight and obesity among Malaysian adults. One of the ways is to increase their awareness on the consequences of being overweight and obese and how to overcome it. This includes conducting a health campaign, educating the public through mass media or through printed materials. The educational printed material for example, serves the purpose to provide information and knowledge to a certain age group and for specific conditions. It is recommended to use educational material prepared by healthcare professional in order to reinforce the verbal communication. Educational material on healthy eating for overweight and obesity has been developed such as 'Eat Right, Move More, Fight Obesity' by the Nutrition Month Malaysia Secretariat and Malaysian Dietary Guideline (NCFFN, 2010). However, none of them specifically focus on Sunnah eating practices as the guideline. The practices of the prophet (always refer as Sunnah), is the record of every act, word, and confirmation of the messenger. Sunnah serves as the second source of Islamic legislation and life while the first one is the Qur'an. Allah (refers to Muslim God) sent the Prophet Muhammad as His messenger to provide the guidance for his follower to obey and adopt in their life (Muhammad, 2013). The Sunnah eating practices which promote the elements of healthy eating was seen as a beneficial aspect to study as it can help to reduce the risk of getting the chronic disease such as, diabetes, coronary heart disease, hyperlipidemia and kidney problem. Moreover, by reducing the risk of getting such diseases, it will, in turn help individual to increase the Quality of Life.

\footnotetext{
* Corresponding author. Tel.: +603-32584540

E-mail address: nurislami@puncakalam.uitm.edu.my
}

ISSN: 2398-4287@ 2017. The Authors. Published for AMER ABRA by e-International Publishing House, Ltd., UK. This is an open access article under the CC BYNC-ND license (http://creativecommons.org/licenses/by-nc-nd/4.0/). Peer-review under responsibility of AMER (Association of Malaysian Environment-Behaviour Researchers), ABRA (Association of Behavioural Researchers on Asians) and cE-Bs (Centre for Environment-Behaviour Studies), Faculty of Architecture, Planning \& Surveying, Universiti Teknologi MARA, Malaysia

DOI: http://dx.doi.org/10.21834/e-bpj.v2i5.692 
The aim of this study is to describe the validation process of an educational booklet for sunnah eating practices to improve the Quality of Life among adults population.

\subsection{Literature Review}

\subsection{Factors and Effects of Overweight and Obesity}

There are many factors that contribute to a person to become overweight. It does not happen as a result of a day or two of excessive energy intake but it happens due to long term habits and dietary practice (Dong et al., 2012) . Overweight and obesity are the results of energy imbalance over a long period of time. The causes of energy imbalance for each individual may be due to the combination of several factors. Individual behaviours, environmental factors, and genetics will all contribute to the complexity of the obesity epidemic. For example, environmental factors such as the availability of fast food restaurants nearby schools or residential areas are looked as one of the contributing factors for people to gain weight by consuming fast food regularly (Currie et al, 2009; Jeffrey et al., 2006). Apart from that, individual behaviours that practice unhealthy eating habits such as regular intake of fried food and high fat snack has also lead to obesity (Yahia et. al, 2004). Consumption of high energy dense food and fast food has all been linked to unhealthy weight among Malaysian (Abdullah et al. 2016).

Lifestyle is another factor that leads to overweight. Although there have been initiatives to promote a healthy lifestyle by developing green spaces for outdoor activities (Mansor \& Harun, 2016), the rate of physical inactivity were still high. Nevertheless, with current technology, most people are leading a sedentary lifestyle at home by staying in front of electronic gadgets or television for surfing, watching and leisure (Janssen et. al, 2004). While in working environment, especially people who stay in the office, working with computer reduce the daily energy expenditure (Duvigneaud et al., 2007).

The effect of obesity on health has been known widely. People with increased Body Mass Index (BMI) have high risk of getting chronic diseases such as cardiovascular diseases, liver problem, diabetics and kidney dysfunction. Being overweight will reduce the productivity of a person and increased the risk factors for many health problems (Carnethon et al., 2004). It is also increasing concern that obesity and overweight people will have implications on their quality of life. People with higher BMl are at risk of lower healthrelated quality of life, which mostly affect the psychological health (Nawi and Ahmad, 2014). Apart from that, an increase in BMI will reduce the cognitive function of a person (Gunstad et al., 2010).

\subsection{Sunnah Eating Practices}

Sunnah serves as the second source of Islamic legislation. The Prophet Muhammad was sent as a messenger to provide the guidance for his follower to obey and adopt in their life. The prophet has lead his life as the role model for human to follow. Everything from the prophet was considered as the Sunnah or prophet's tradition (Muhammad, 2013). Therefore, what the prophet did and said and also what his companions did and he agreed to them are the sources of Islamic teaching. The prophetic or Sunnah way of eating has been widely discussed as the best way to practice for human wellbeing. One of the reasons to claim that is, Prophet Muhammad has never been diagnosed with any disease throughout his lifetime (Al-Jauziyah \& Jalil, 2013). The Sunnah eating practices which promotes to eat in a small amount, to eat slowly, to avoid gluttonies, to eat in upright positions and many other elements are the approach to healthy eating. Nevertheless, many Muslim people are seen to have the problem of overweight and obesity as the result of the unhealthy eating practices (Muhammad, 2013).

Nowadays, faith-based elements have been included by researchers in their studies as a mediator to change people's behaviour. It is also included in the intervention study which known as a faith-based intervention; the term given to an intervention that includes religion element in it. There are several interventions of weight loss program that use religion as an added value. Among the faithbased interventions is to include Islamic teaching as the mediator to change dietary behaviour in controlling weight (Teng et al., 2011; Suriani, et al., 2015). It is found that the number of subjects that practiced food quantity control was significantly increased in the intervention and controlled group, but the increment percentage was higher in the intervention group (Suriani et al., 2015).

\subsection{Nutrition Education Tools}

Education is important to change people's behaviour. Without the right and proper education, people would not have the access to the reliable information and true knowledge. The nutrition education tools were provided as the medium to convey the dietary information and knowledge to the community. It is also to reinforce the verbal communication conveyed by the health educator for example dietitians and nutritionists (Clark et al., 2005). People who have attended any health talk or presentations might forget what has been delivered prior to them when they are at home. Thus, education tools would be their guideline or reference afterwards (Kessel, 2003). This will also help other family members or spouses who were not around during the presentations or counselling sessions to be able to get the information.

Education tools have to undergo evaluation and validation before it can be use. The evaluation is important to make sure that the content, layout and design are acceptable for the target audience (Oliveira, 2014; Hawe et al. 1994). The assessment by the target audience will help the educational tools developer to meet the needs and understandings of the reader. Meanwhile, the content validation were done to ensure that the information in the booklet were valid and accurate. For example, this booklet which involves dietetics knowledge as well as Islamic knowledge needs the content expert of both fields to be validated. Therefore, the experts for the content validation involved during the development of the booklets are dietitians and Muslim scholars. Apart from that, the finalised booklet will be validated by the judges using the judges-based instrument (Polit and Beck, 2006). The instrument used to validate the 
content and the appearance of the booklet. It is found that, nutrition education can help in improving the quality of life of people with disease (Baghianimoghadam et al., 2009).

\subsection{Methodology}

\subsection{Development of Educational Booklet}

The process of developing the booklet involves several steps (Wizowski et al., 2006). The first step is to form a team that is responsible and can work closely throughout the development phase. The team should comprise of people who have relation to the intended audience and to the topic of the education material. For this educational material, a team comprised of dietitians, nutritionist and Muslim scholars were formed. The dietitians and nutritionists were responsible in discussing the appropriate input of the educational material. Muslim scholars on the other hand were responsible for validating the input from Quranic verses and Hadith.

The second step is to identify the purpose of the educational booklet and the intended audience. The purpose of the booklet was to provide guidelines on healthy eating with the input from Sunnah eating practices. Since the Sunnah eating practices have the element of healthy eating and promotion of weight loss, it is beneficial to set the intended audience to be among people who are overweight. For the age group, the middle-aged adult was chosen as it has the highest prevalence of overweight. Therefore, the intended audience were the overweight middle-aged adult.

The third step is to assess the available materials. For this educational booklet, an extensive searched on available articles and books regarding Sunnah eating practices were conducted. After retrieving related articles and books, thorough reading was done before proceed to the fourth step which is to decide the content. The content should have a practical approach and can be easily understood by the adult. In the process of constructing the content of the booklet, the recommendations on types of foods and lifestyle habit were based on the suitability for Malaysian. Regarding the quranic verses and hadith to be included as the content, it had been validated for its authority by two Muslim scholars, one which is an expert in the Quran and the other one which is an expert in the Hadith.

The fifth step is to prepare the first draft. It includes writing in our own words to maintain the originality of the booklet. The booklet should be interactive and use simple words. This is to ensure reader can understand and can apply the guidelines. The size of the booklet has also been decided to be A- 5 size considering that it should be handy to be carry and view by the reader as a daily guideline. The draft has been prepared in the booklet form.

Lastly, for the illustration and design, a professional designer was assigned to make sure that the message and outlook of the booklet are more presentable and effective. The designed booklet was then being revised again by the research team and a few amendments have been done until the finalised booklet is produced. The next step was the validation of the educational booklet by judges and adults.

\subsection{Validation of Educational Booklet by Judges}

The educational booklet has to be validated by the judges to make sure that the recommendations included were in line with the dietetic practices and provide accurate health information. Apart from that, it is important that the judges to validate whether the booklet is relevant for adults in terms of the content and appearance. For the validation by the judges, the judgement-based instrument was used (Polit and Beck, 2006). Apart from that, judges are recommended to provide comments and suggestions to improve the booklet. Recommendations by judges were accepted and included in the final version of the booklet.

A total of 22 judges participated in the validation process. The formula for the sample size was $n=Z a^{2} \cdot P(1-P) / e^{2}$, where $P$ is the expected proportion of judges, indicating the adequacy of each item, while "e" indicates the acceptable proportional difference compared to what would be expected. A confidence level was set at $95 \%$, indicating that at least $70 \%$ of judges would have to rate the item as appropriate. Therefore, the values used for the calculation were $Z a^{2}=1.96 ; P=0.85 ; e=0.15$.

The selection of judges was by convenience where they were chosen among health professionals like dietitians, nutritionists, researchers in health science fields. 22 judges were approach to participate in validating the booklet. To conduct the validity index (CVI), three approaches were followed; (i) I-CVI (level content validity index): the I-CVI was calculated by the number of judges that evaluated the item as relevant or very relevant, (ii) S-CVI/AVE (scale-level content validity index, average calculation method) is the proportion of scale items rated as relevant and very relevant by each judge, (iii) S-CVI (scale-level content validity index): mean of the proportion of items evaluated as relevant and very relevant by the judges. An index $>0.80$ were considered adequate for the content validity.

\subsection{Validation of Educational Booklet by Adult}

The booklet was then undergoing validation by adults. 20 adults were involved in the validation of the booklet. The adults were asked to evaluate the content and layout of the educational booklet. They were approach individually at home and at the mosque. The criteria for the adult are 40-59 years old (middle-aged category), able to read, and write and have no mental disabilities and have no vision problem. They were asked to fill a demographic part before answering a self-administered questionnaire. They were given ample time to read the booklet before attempting the questionnaire. The evaluation on content, layout and design is based on the suggestion by Hawe et al. (1994). The adults were also encouraged to give any comments and suggestions for improvement of the booklet. A research assistant was around for any inquiries or assistance regarding the questionnaire. 


\subsection{Findings}

\subsection{Educational Booklet}

The title of the education booklet is 'Guidelines of Eating and Physical Activity based on Sunnah' (Figure 1). The booklet was developed after extensive literature on eating practices of the prophet that have the elements of healthy eating. It contains seven guidelines on Sunnah eating practices and physical activity as shown in Table 1. It was developed in Malay language and can be as a reference guide for adults who are overweight.

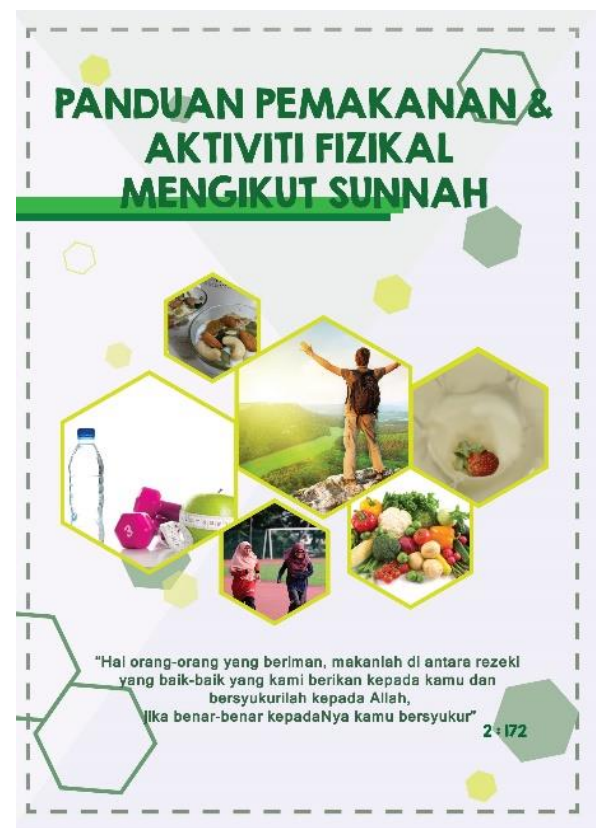

Figure 1. Booklet on 'Guidelines of Eating and Physical Activity based on Sunnah'

Table 1. Practices guidelines in the educational booklet

\begin{tabular}{ll}
\hline \multicolumn{2}{c}{ Educational Booklet (7 Practices) } \\
\hline Practice 1: & Eat according to the body requirement \\
Practice 2: & Choose healthy foods \\
Practice 3: & Eat slowly \\
Practice 4: & Do not recline while eating \\
Practice 5: & Drink enough water \\
Practice 6: & Increase physical activity \\
Practice 7: & Sunnah Foods \\
& \\
\hline
\end{tabular}

The final version of the booklet is an A-5 size with 48 pages, starting with a brief explanation about the book in the introduction part, and the importance of the educational booklet to promote awareness to the reader. The seven practices were presented with illustration like tables and figures to ensure that subject can easily understand the content. For every practice, there were supports whether from quranic verses or hadiths of the prophet.

The first practice is to encourage the reader to eat according to the body requirement. There is a brief explanation on why to eat according to our body requirement. There is a Hadith on the purpose of food consumption to a human. There is a recommendation to avoid eating excessively which is supported by a quranic verse that prevents us from doing so. Include in the practice is the steps on how to know our energy requirements. Readers are guided on how to calculate Body Mass Index (BMI) to know the BMI classification. After knowing the BMI classifications, the reader will have to chose the factor in Quick-method for energy calculation. There was 7 days menu prepared for three energy requirements which are 1,200 calories, 1,4000 calories and 1,600 calories.

The second practice is about choosing healthy foods. There was short explanation provided and a Quranic verse that encourage to choose healthy and permissible (halal) foods. There were recommendations on how to choose and prepare healthy foods. The third practice was about eating slowly. Eating slowly has many benefits to the human for example, by munching slowly, the satiety signal will be sending to the brain. This, in turn, will make the person to feel full quicker and to eat food in a small quantity.

The steps on how to eat slowly were also provided in this section.

The fourth practice is not to recline while eating. The prophet dislikes people who are eating while reclining against the wall or any platform. He clearly mentioned it in the hadith that is provided in this practice. Figures on the upright and recline position were provided to make it clear for the reader to follow (Figure 2). 


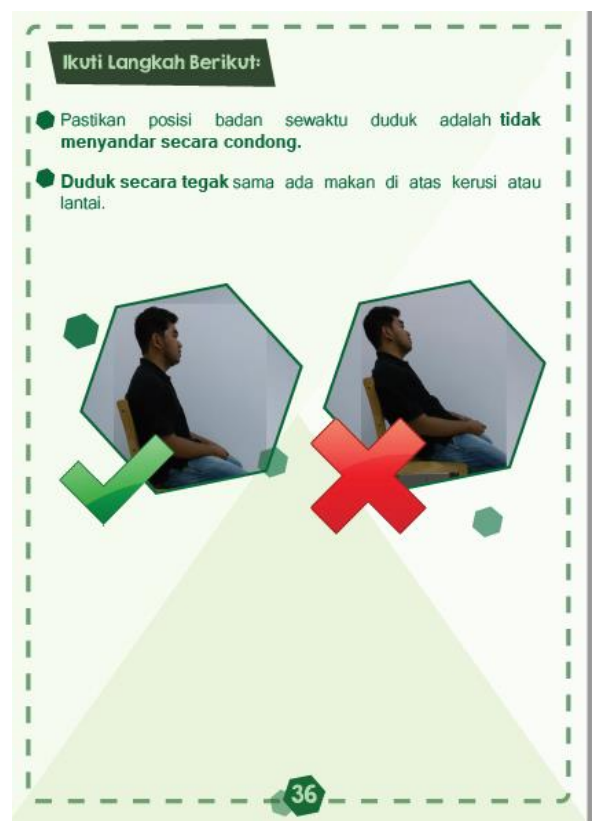

Figure 2. Illustrations the right sitting technique

The fifth practice is about drinking enough water. The prophet has conveyed the right way of drinking which is to drink in three gulps. The practice is important to quench excessive thirst and the health consequences that might happen when drinking only in a gulp. The sixth practice is to increase physical activity. There were many physical activities that can be done to ensure that our body is healthy and fit. In this section, the recommendation the duration and types of physical activities that can be done is provided for the reader to follow (Figure 3).

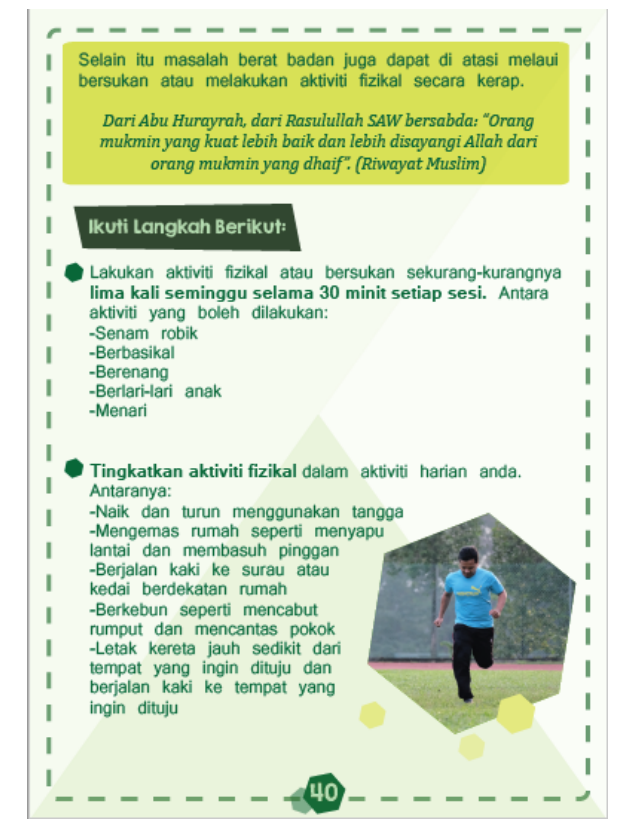

Figure 3. The recommendations on several types of physical activities

The last practice is to eat Sunnah foods. Sunnah foods refer to foods that are preferable by the prophet. There is three example of Sunnah foods include in this section which are dates, honey and black cumins (Habbatus Sauda'). All the foods were being described about the benefits of consuming them in this last section.

\subsection{Validation of Educational Booklet by Judges}

The validation of the booklet had been done by 22 judges. The judges who were from health professional backgrounds were approached and agreed to validate the booklet. They return the completed booklet and also provide their insights comment and 
suggestions to improve the booklet. Among 22 judges, 18 were dietitians (81\%), 2 nurses (9\%) and 2 postgraduate students in Health Science $(9 \%)$. Regarding the level of education, all the judges were degree holders (100\%).

The seven items of the instrument had 100\% proportion of relevance (S-CVI/AVE) among 19 judges. Meanwhile, the S-CVI value obtained was 0.93 and the mean I-CVI was 0.97 . For each item, the I-CVI rated separately achieved the value of more than 0.80 (Table 3). Regarding the comment and suggestions on the improvement, $25 \%$ of the judges commented that the booklet has been designed to meet the understanding people who are not in the health science field. The words used can be easily understood (10\%). The summary of the comments and suggestions were included in Table 4.

Table 3. Evaluation of the booklet regarding the seven items of the instrument, according to the relevance

\begin{tabular}{|l|c|c|c|c|c|c|c|c|c|c|c|c|}
\hline Items & \multicolumn{10}{|c|}{ Judges } & \multicolumn{1}{|c|}{} \\
\cline { 2 - 13 } & $\mathrm{X}$ & 2 & 3 & 4 & 5 & 6 & 7 & 8 & 9 & 10 & 11 & 12 \\
\hline $\begin{array}{l}\text { 1. The language and sentence use is } \\
\text { clear and easy to understand }\end{array}$ & $\mathrm{X}$ & $\mathrm{X}$ & $\mathrm{X}$ & $\mathrm{X}$ & $\mathrm{X}$ & $\mathrm{X}$ & $\mathrm{X}$ & $\mathrm{X}$ & $\mathrm{X}$ & $\mathrm{X}$ & $\mathrm{X}$ & $\mathrm{X}$ \\
\hline $\begin{array}{l}\text { 2. The colour combination used is } \\
\text { suitable for adults }\end{array}$ & $\mathrm{X}$ & $\mathrm{X}$ & $\mathrm{X}$ & $\mathrm{X}$ & $\mathrm{X}$ & $\mathrm{X}$ & $\mathrm{X}$ & $\mathrm{X}$ & $\mathrm{X}$ & $\mathrm{X}$ & $\mathrm{X}$ & $\mathrm{X}$ \\
\hline $\begin{array}{l}\text { 3. The font size is suitable to be read by } \\
\text { adults }\end{array}$ & $\mathrm{X}$ & $\mathrm{X}$ & $\mathrm{X}$ & $\mathrm{X}$ & $\mathrm{X}$ & $\mathrm{X}$ & $\mathrm{X}$ & $\mathrm{X}$ & $\mathrm{X}$ & - & $\mathrm{X}$ & $\mathrm{X}$ \\
\hline $\begin{array}{l}\text { 4. Illustration used has suitable design for } \\
\text { adults }\end{array}$ & $\mathrm{X}$ & $\mathrm{X}$ & $\mathrm{X}$ & $\mathrm{X}$ & $\mathrm{X}$ & $\mathrm{X}$ & $\mathrm{X}$ & $\mathrm{X}$ & $\mathrm{X}$ & - & $\mathrm{X}$ & $\mathrm{X}$ \\
\hline $\begin{array}{l}\text { 5. Illustration/table used are necessary to } \\
\text { understand the content }\end{array}$ & $\mathrm{X}$ & $\mathrm{X}$ & $\mathrm{X}$ & $\mathrm{X}$ & $\mathrm{X}$ & $\mathrm{X}$ & $\mathrm{X}$ & $\mathrm{X}$ & $\mathrm{X}$ & $\mathrm{X}$ & $\mathrm{X}$ & $\mathrm{X}$ \\
\hline $\begin{array}{l}\text { 6. Illustration/table and text motivate } \\
\text { reader/adult to understand the practice }\end{array}$ & $\mathrm{X}$ & $\mathrm{X}$ & $\mathrm{X}$ & $\mathrm{X}$ & $\mathrm{X}$ & $\mathrm{X}$ & $\mathrm{X}$ & $\mathrm{X}$ & $\mathrm{X}$ & $\mathrm{X}$ & $\mathrm{X}$ & $\mathrm{X}$ \\
\hline $\begin{array}{l}\text { 7. Applicability of the booklet for } \\
\text { guidelines in healthy eating }\end{array}$ & $\mathrm{X}$ & $\mathrm{X}$ & $\mathrm{X}$ & $\mathrm{X}$ & $\mathrm{X}$ & $\mathrm{X}$ & $\mathrm{X}$ & $\mathrm{X}$ & $\mathrm{X}$ & - & $\mathrm{X}$ & $\mathrm{X}$ \\
\hline Proportion of relevance S-CVI/AVE & 1 & 1 & 1 & 1 & 1 & 1 & 1 & 1 & 1 & 0.57 & 1 & 1 \\
\hline
\end{tabular}

\begin{tabular}{|l|c|c|c|c|c|c|c|c|c|c|c|c|}
\hline Items & \multicolumn{10}{|c|}{ Judges } & \multicolumn{1}{|c|}{} \\
\cline { 2 - 14 } & 13 & 14 & 15 & 16 & 17 & 18 & 19 & 20 & 21 & 22 & Aval. ${ }^{*}$ & I-CVI \\
\hline $\begin{array}{l}\text { 1. The language and sentence use is } \\
\text { clear and easy to understand }\end{array}$ & $\mathrm{X}$ & $\mathrm{X}$ & $\mathrm{X}$ & $\mathrm{X}$ & $\mathrm{X}$ & $\mathrm{X}$ & $\mathrm{X}$ & $\mathrm{X}$ & $\mathrm{X}$ & $\mathrm{X}$ & 22 & 1 \\
\hline $\begin{array}{l}\text { 2. The colour combination used is } \\
\text { suitable for adults }\end{array}$ & $\mathrm{X}$ & $\mathrm{X}$ & $\mathrm{X}$ & $\mathrm{X}$ & $\mathrm{X}$ & $\mathrm{X}$ & $\mathrm{X}$ & $\mathrm{X}$ & $\mathrm{X}$ & $\mathrm{X}$ & 22 & 1 \\
\hline $\begin{array}{l}\text { 3. The font size is suitable to be read by } \\
\text { adults }\end{array}$ & - & $\mathrm{X}$ & $\mathrm{X}$ & $\mathrm{X}$ & $\mathrm{X}$ & $\mathrm{X}$ & $\mathrm{X}$ & $\mathrm{X}$ & $\mathrm{X}$ & $\mathrm{X}$ & 20 & 0.91 \\
\hline $\begin{array}{l}\text { 4. llustration used has sutable design for } \\
\text { adults }\end{array}$ & $\mathrm{X}$ & $\mathrm{X}$ & $\mathrm{X}$ & $\mathrm{X}$ & $\mathrm{X}$ & $\mathrm{X}$ & $\mathrm{X}$ & $\mathrm{X}$ & $\mathrm{X}$ & $\mathrm{X}$ & 21 & 0.95 \\
\hline $\begin{array}{l}\text { 5. Illustration/table used are necessary to } \\
\text { understand the content }\end{array}$ & $\mathrm{X}$ & $\mathrm{X}$ & $\mathrm{X}$ & $\mathrm{X}$ & $\mathrm{X}$ & $\mathrm{X}$ & $\mathrm{X}$ & $\mathrm{X}$ & $\mathrm{X}$ & $\mathrm{X}$ & 22 & 1 \\
\hline $\begin{array}{l}\text { 6. Ilustration/table and text motivate } \\
\text { reader/adult to understand the practice }\end{array}$ & $\mathrm{X}$ & $\mathrm{X}$ & $\mathrm{X}$ & $\mathrm{X}$ & $\mathrm{X}$ & - & $\mathrm{X}$ & $\mathrm{X}$ & $\mathrm{X}$ & $\mathrm{X}$ & 21 & 0.95 \\
\hline $\begin{array}{l}\text { 7. Applicability of the booklet for } \\
\text { guidelines in healthy eating }\end{array}$ & $\mathrm{X}$ & $\mathrm{X}$ & $\mathrm{X}$ & $\mathrm{X}$ & $\mathrm{X}$ & $\mathrm{X}$ & $\mathrm{X}$ & $\mathrm{X}$ & $\mathrm{X}$ & $\mathrm{X}$ & 21 & 0.95 \\
\hline Proportion of relevance S-CVI/AVE & 0.86 & 1 & 1 & 1 & 1 & 0.86 & 1 & 1 & 1 & 1 & - & - \\
\hline
\end{tabular}

*Number of very relevant or relevant reviews considered by the judges

Table 4. Summary of the judges' suggestions and comments

\begin{tabular}{ll}
\hline & Recommendations of the Judges \\
\hline Judge 3 & Not to use lengthy sentences. \\
Judge 4 & Use the colour that is brighter, so that adult people can easily read the articles. \\
Judge 6 & Add in more graphic to make the booklet more interesting. \\
Judge 9 & Use more scientific evidence to support the recommendations in the booklet. \\
Judge $10 \& 13$ & The size of the household measurement should be bigger to make it clearer for the reader. \\
\hline
\end{tabular}

\subsection{Validation of Educational Booklet by Adult}

The educational booklets were given to 20 adults to assess the acceptance. The adults aged 41 to 59 years old with the mean age of 49.95 years old. $60 \%$ of adult subjects were women while $40 \%$ were men. Regarding the level of education of the adults, most of the subjects were degree holder (55\%). For the family income, $50 \%$ of the subjects had more than RM4,000 per month, $45 \%$ had between $\mathrm{RM} 2,000$ to RM4,000 income and only $5 \%$ has less than RM2,000 income. For the assessment on understanding about the content of the book, all subjects (100\%) understand the content of the booklet.

The booklet was positively evaluated in terms of the colour, font and graphic. $10 \%$ of the adults suggested that a bright colour should be use to make it look more interesting, while $10 \%$ also suggested that a bigger picture size should be put. There were also comments on the front cover to have colour background instead of white colour (5\%). 
Table 5. Analysis of acceptance of the educational booklet among adult subjects

\begin{tabular}{|c|c|c|c|}
\hline \multirow[t]{2}{*}{ Parameters } & \multicolumn{3}{|c|}{ Subjects, n (\%) } \\
\hline & Men $(n=8)$ & Women $(n=12)$ & Total $(n=20)$ \\
\hline \multicolumn{4}{|l|}{ Understanding of information } \\
\hline Understood very much & $5(45.5)$ & $6(54.5)$ & $11(55.0)$ \\
\hline Understand & $3(33.3)$ & $6(66.6)$ & $9(45.0)$ \\
\hline Do not understand & $0(0)$ & $0(0)$ & $0(0)$ \\
\hline \multicolumn{4}{|c|}{ Aspects that facilitate comprehension ${ }^{a}$} \\
\hline Terminology easily understood & $2(40.0)$ & $3(60.0)$ & $15(75.0)$ \\
\hline Sentences use were clear & $4(30.8)$ & $9(69.2)$ & $13(65.0)$ \\
\hline Illustration/Table use were clear & $3(42.9)$ & $4(57.1)$ & $7(35.0)$ \\
\hline Suitability of recommendation & $3(75.0)$ & $1(25.0)$ & $4(20.0)$ \\
\hline \multicolumn{4}{|l|}{ Suitability of figures/illustrations } \\
\hline Yes & $7(36.8)$ & $12(63.2)$ & $19(95.0)$ \\
\hline No & $1(12.5)$ & $0(0.0)$ & $1(5.0)$ \\
\hline \multicolumn{4}{|l|}{ Colour combination } \\
\hline Attractive & $6(42.9)$ & $8(57.1)$ & $14(70.0)$ \\
\hline Less/Not Attractive & $2(33.3)$ & $4(66.7)$ & $6(30.0)$ \\
\hline \multicolumn{4}{|l|}{ Font Size } \\
\hline Easy to read & $8(40.0)$ & $12(60.0)$ & $20(100.0)$ \\
\hline Difficult to read & $0(0)$ & $0(0)$ & $0(0)$ \\
\hline \multicolumn{4}{|c|}{ Illustration/table were necessary to understand the content } \\
\hline Very Relevant & $5(38.5)$ & $8(61.5 \%)$ & $13(65.0)$ \\
\hline Relevant & $3(42.9)$ & $4(57.1)$ & $7(35.0)$ \\
\hline Not Relevant & $0(0)$ & $0(0)$ & $0(0)$ \\
\hline \multicolumn{4}{|c|}{ Illustration/table motivate reader to understand } \\
\hline Very relevant & $5(38.5)$ & $8(61.5)$ & $13(65.0)$ \\
\hline Relevant & $2(33.3)$ & $4(66.7)$ & $6(30.0)$ \\
\hline Not Relevant & $1(5.0)$ & $0(0)$ & $1(5.0)$ \\
\hline
\end{tabular}

aCumulative Percentages more than $100 \%$ due to multiple answers.

\subsection{Discussion}

The educational booklet has been prepared and developed for adults who are overweight. The booklet is prepared to facilitate nutritionists and dietitians in giving diet advice and recommendations to curb with increasing number of overweight people in Malaysia. Concerning the rise of faith-based studies and interventions to overcome the health problem, we have found out that there was no such studies or booklet developed that has included the element of Sunnah eating practices as suggestions for people who wants to reduce weight and lead a healthy lifestyle. According to the extensive literature done before, the prophet himself has never been diagnosed with any health problem and has practiced many eating practices which have the elements of healthy eating that could be included in guidelines for healthy eating (Al-Jauziyah \& Jalil, 2013). Among the eating practices promoted by the prophet were to eat only to eliminate the feeling of hunger is significance in reducing the portion size of a meal taken at a time. Apart from that, the prophet also encourages people to eat slowly has been seen as a way to allow that satiety signal to be sent to the brain which leads to faster satiation. These two examples in turn lead to reduce of calorie intake and weight loss. By following the Sunnah practices, an individual may improve his or her health condition by experiencing weight loss and reduce the chance of suffering from chronic disease. Moreover, the booklet is an educational tool to increase the awareness of healthy eating and lifestyle of the overweight adult. By providing health education and increasing the awareness of subjects, the quality of life of subjects will improve (Abdullah² et al., 2016; Baghianimoghada et al., 2009).

Printed materials such as the educational booklet were prepared as a valuable tool for the subjects to learn and facilitate the advice by the nutritionists and dietitians but it cannot substitute the verbal communications (Clark et al. 2005). Apart from that, an attractive and well-designed educational material will help to increase subject's knowledge and compliance to follow the guideline (You et al., 2011). Subjects who expose to many information will subsequently forget what they have been told or recall them incorrectly (Kessel, 2003). Thus, printed materials help subjects to recall better and to refer again when they need to apply it in their daily life. It can also become a reference for other family members or spouse who are not around during the learning session.

The guideline has been designed to include the eating practices of the prophet with supported hadith and quranic verses and recommendations from dietetic aspects for subjects to follow. The illustrations, figures and tables were prepared to assist subjects in further understanding of the practices. The booklet has also provided seven days menu for three different energy requirements for the subjects to follow. The menu suggested in the booklet were common local foods so that the recommendations can be easily followed and realistic (Albert et al., 2007). 
From the results of acceptance towards the educational booklet, all the adult subjects understood the information provided and prefer the A-5 size of the booklet. The size is handy for them to bring and is comfortable to refer and read. The font size used was $12-$ point and it was accepted by the subjects. The optimal size of 9-12 points educational package is suggested by Fuchs (2008). There were subjects who found out that the colour combination was less or not attractive. They had suggested that brighter colour should be used and to use colour background for front cover.

The recommendations of judges to include more illustrations and figures are in line with the suggestion by Aldridge (2004). The suggestions and comments were included in the final version of the booklet after evaluating the results both from the adults and the judges. The booklet has achieved the value of average I-CVI of 0.97 , which is more than $>0.80$ and S-CVI value of 0.93 . Therefore, quantitatively, the booklet has been validated.

\subsection{Conclusion}

The educational booklet has been validated by judges and adults. The validation is done pertaining to its content and relevance. The development has involved the planning group comprises of researchers, dietitians, Muslim scholars as well as the professional designer. The final version has been produced after considering the review by the judges and adults. Therefore, the booklet is relevant and can be used as a teaching material by health care provider especially nutritionists and dietitians.

\section{Acknowledgements}

The authors wish to thank all the participating adults and judges of this study. The study was funded by Universiti Teknologi MARA (600-IRMI/DANA 5/3/LESTARI (0094/2016)).

\section{References}

Abdullah'1, NN, Mohamad Mokhtar, M, Abu Bakar, MH, \& Al-Kubaisy, W (2016). Fast Food Consumption and Obesity. Journal Of ASIAN Behavioural Studies, ISSN: 2180-4567, 6(22).

Abdullah22, J., Sayuti, N. M., Arshad, A. A. M., \& Embong, M. R. (2016). Quality of Life at Resettlement Project in Pahang, Malaysia. Asian Journal of EnvironmentBehaviour Studies, ISSN: 1394-0384, 7(27).

Albert, J.L., Samuda, P.M., Molina, V., Regis, T., Severin, M., Finlay, B. \& Prevost, J.L. 2007. Developing food-based dietary guidelines to promote healthy diets and lifestyles in the Eastern Caribbean. J. Nutr. Educ. Behav. 39: 343-350.

Aldridge, M. D. (2004). Writing and designing readable patient education materials. Nephrology Nursing Journal, 31(4), 373.

Baghianimoghadam, M. H., Ardekani, M., \& Baghianimoghadam, B. (2009). Effect of education on improvement of quality of life by SF-20 in type 2 diabetic patients. Acta Medica Indonesiana, 41(4), 175-180.

Al-Jauziyah, I. Q., \& Jalil, N. A. (2013). Perubatan Rasulullah. (P. E. Al-Hidayah, Ed.) (First Edit). Al-Hidayah House of Publishers Sdn. Bhd.

Clark, P.A., Drain, M., Gessel, S.B., Mylod, D.M., Kaldeberg, D.O. \& Hamilton, J. 2005. Patient Perception of quality in discharge instruction. Patient Education and Counselling 59: 56-68.

Blissmer, B., Riebe, D., Dye, G., Ruggiero, L., Greene, G., \& Caldwell, M. (2006). Health-related quality of life following a clinical weight loss intervention among overweight and obese adults: intervention and 24 month follow-up effects. Health and Quality of Life Outcomes, 4, 43. http://doi.org/10.1186/1477-7525-4-43

Carnethon, M. R., Loria, C. M., Hill, J. O., Sidney, S., Savage, P. J., \& Liu, K. (2004). Risk Factors for the Metabolic Syndrome: The Coronary Artery Risk Development in Young Adults (CARDIA) study, 1985-2001. Diabetes Care. http://doi.org/10.2337/diacare.27.11.2707

Currie, J., DellaVigna, S., Moretti, E., \& Pathania, V. (2009). The effect of fast food restaurants on obesity and weight gain (No. w14721). National Bureau of Economic Research.

Dong, H. J., Unosson, M., Wressle, E., \& Marcusson, J. (2012). Health consequences associated with being overweight or obese: A Swedish population-based study of 85-year-olds. Journal of the American Geriatrics Society, 60(2), 243-250. http://doi.org/10.1111/j.1532-5415.2011.03827.

Duvigneaud, N., Wijndaele, K., Matton, L., Deriemaeker, P., Philippaerts, R., Lefevre, J., Thomis, M., \& Duquet, W. (2007). Socio-economic and lifestyle factors associated with overweight in Flemish adult men and women. BMC Public Health, 7(1), 1.

Fuchs, J., Heyer, T., Langenhan,D \& Hippius, M. 2008. Influence of font sizes on the readability and comprehensibility of package inserts. Pharm. Ind. 70(5): 584-592

Gunstad, J., Rice, C., Ferrucci, L., \& Zonderman, A. B. (2010). Longitudinal Examination of Obesity and Cognitive Function : Results from the Baltimore Longitudinal Study of Aging, 222-229. http://doi.org/10.1159/000297742

Hawe, P., Degeling, D., Hall,J. \& Brierly, A. 1994. Evaluating Health Promotion, A Health Workers' Guide. Sydney: MacLennan \& Petty Pty Limited.

Janssen, I., Katzmarzyk, P. T., Boyce, W. F., King, M. A., \& Pickett, W. (2004). Overweight and obesity in Canadian adolescents and their associations with dietary habits and physical activity patterns. Journal of adolescent health, 35(5), 360-367. 
Jeffery, R. W., Baxter, J., McGuire, M., \& Linde, J. (2006). Are fast food restaurants an environmental risk factor for obesity?. International Journal of Behavioral Nutrition and Physical Activity, 3(1), 2.

Kessels. R. (2003). Patients' memory for medical information. Journal of the Royal Society of Medicine. 96(5), 217-222.

Khor GL, Noor Safiza MN, Rahmah R, Jamaluddin AR, Kee CC, Geeta A, Jamaiyah H, Suzana S, Wong NF, Ahmad Ali Z, R. A. \& A. F. Y. (2008). The Third National Health and Morbidity Survey (NHMS III) 2006: Nutritional Status of Children Aged 0 to Below 18 Years and Adults Aged 18 Years and Above. 23 Rd Scientific Conference of the Nutrition Society of Malaysia, 14(March), 11.

Mansor, M, \& Harun, NZ (2016). Health Issues and Green Space as Reinforcement for a Healthy Lifestyle in Malaysia. Journal Of ASIAN Behavioural Studies, ISSN 2180-4567, 5(18), 57-66. doi:10.21834/jabs.v5i18.87.

Muhammad, R. J. (2013). Eating and Drinking Conduct of. In Message of Thaqalayn (Volume 15, pp. 97-122).

National Coordinating Commitee of Food and Nutrition (NCCFN). 2010. Malaysian Dietary Guideline. Kuala Lumpur: NCCFN.

Nawi, A. M., \& Ahmad, N. (2014). Impaired quality of life in overweight and obese young adults in rural Malaysia. Brunei International Medical Journal, $10(3), 145-152$.

Oliveira, S. C. D., Lopes, M. V. D. O., \& Fernandes, A. F. C. (2014). Development and validation of an educational booklet for healthy eating during pregnancy. Revista latino-americana de enfermagem, 22(4), 611-620.

Polit, D. F., \& Beck, C. T. (2006). The content validity index: are you sure you know what's being reported? Critique and recommendations. Research in nursing \& health, 29(5), 489-497.

Suriani, I., Shamsuddin, K., Khalib, A. L., Hazizi, A. S., \& Fadhlan, M. O. (2015). The effect of Ramadan weight loss on body composition of overweight and obese Muslims in University Putra Malaysia. International Journal of Public Health and Clinical Sciences, 2(1), 61-68.

Teng, N. I. M. F., Shahar, S., Manaf, Z. A., Das, S. K., Taha, C. S. C., \& Ngah, W. Z. W. (2011). Efficacy of fasting calorie restriction on quality of life among aging men. Physiology and Behavior, 104(5), 1059-1064. http://doi.org/10.1016/j.physbeh.2011.07.007

Terrie, Y. C. $\quad$ (2014, October 9). Overcoming Obesity. Retrieved August 05, 2016, from http://www.pharmacytimes.com/publications/issue/2014/october2014/overcoming-obesity/P-1

Wizowski, L., Harper, T., \& Hutchings, T. 2006. Writing Health Information for Patients and Families: A Guide to Creating Patient education Materials That Are Easy to Read, Understand and Use. Hamilton, ON: Media Production Services.

Yahia, N., Achkar, A., Abdallah, A., \& Rizk, S. (2008). Eating habits and obesity among Lebanese university students. Nutrition journal, 7(1), 32.

You, W., Wolff, M., Bailey, S. \& Grobman, W. (2012). Improving patient understanding of preeclampsia: a randomized controlled trial. American Journal of Obstetrics and Gynecology. 206(5): 431.e1-5 